\title{
Factors that Influence Chinese Outbound Tourists' Intention to Consume Local Food
}

\section{Wantanee Suntikul, Stephen Pratt \& Yu Wing Johnny Chong}

To cite this article: Wantanee Suntikul, Stephen Pratt \& Yu Wing Johnny Chong (2020) Factors that Influence Chinese Outbound Tourists' Intention to Consume Local Food, Journal of China Tourism Research, 16:2, 230-247, DOI: 10.1080/19388160.2019.1625841

To link to this article: https://doi.org/10.1080/19388160.2019.1625841

\section{Published online: 14 Jun 2019.}

\section{Submit your article to this journal $\sqsubset$}

山 Article views: 140

Q View related articles $\asymp$

View Crossmark data $\nearrow$ 


\title{
Factors that Influence Chinese Outbound Tourists' Intention to Consume Local Food
}

\author{
Wantanee Suntikul $\left(\mathbb{D}^{\mathrm{a}}\right.$, Stephen Pratt $\mathbb{B}^{\mathrm{b}}$ and Yu Wing Johnny Chong ${ }^{\mathrm{a}}$
}

aSchool of Hotel and Tourism Management, The Hong Kong Polytechnic University, Kowloon, Hong Kong SAR, China; 'bSchool of Tourism \& Hospitality Management, The University of the South Pacific, Suva, Fiji

\begin{abstract}
Food consumption is an essential activity for tourists. Food can be used for destination marketing to attract travellers, and is one of the main purposes of travel for Chinese tourists. This study investigates the factors that motivate Chinese tourists' intention to consume local food during their travels. Using a quantitative study of 308 mainland Chinese tourists to Hong Kong, we find that these tourists value local and traditional food experiences. The physical surroundings and prestige of the food experience are Chinese tourists' major concerns for dining experiences. Local food consumed at the destination is a way to escape from the routine and acquire knowledge of the local culture. The sensory appeal brought by local cuisines also motivate Chinese tourists to consume local foods. These results can assist destination marketers and local restaurateurs to increasing the attractiveness of their destinations and restaurants.
\end{abstract}

\section{影响内地出境游客当地餐饮消费意愿之因素}

\begin{abstract}
摘要
餐饮消费是游客必不可少的活动。美食可以用作目的地营销吸引 旅客, 是内地游客旅游的主要目的之一。本研究调查了哪些因素 激发内地游客在旅游期间消费当地美食之意向。通过对 308 名赴 香港旅游的内地游客进行定量研究, 我们发现这些游客非常重视 当地和传统的美食体验。物理环境和慕名美食体验是内地游客对 用餐体验的主要关注。在目的地消费当地美食是摆脱日常单调和 了解当地文化的一种方式。当地美食带来的感官吸引激励内地游 客消费当地美食。这些结果可以帮助目的地营销者和当地餐馆老 板提高目的地与餐饮之吸引力。
\end{abstract}

\section{ARTICLE HISTORY}

Received 21 January 2019

Accepted 30 April 2019

\section{KEYWORDS}

Local food; food tourism; gastronomy; food experience; culinary tourism; Chinese tourists

\section{关键词}

当地美食; 美食旅游; 美食; 美食体验; 烹饪旅游; 内地 游客

\section{Introduction}

Food is a critical and obligatory component of tourists' travel experience. Culinary consumption can be a primary motivator to travel, and is an area of expenditure for which tourists are less willing to cut costs (Ottenbacher, Harrington, Fauser, \& Loewenhagen, 2016; Stone, Soulard, Migacz, \& Wolf, 2018; UNWTO, 2017). Enjoying food at a destination is a way to experience an important facet of the local culture 
(Mitchell \& Hall, 2003). Beyond cuisine itself, food culture also involves other intangible elements such as dining etiquette, service style, specialty ingredients and preparation methods. The experience of local foods at a destination thus involves facets beyond the dishes themselves, to include the environments within which the food is bought and served, and the customs and practices surrounding food preparation and consumption. The recipes, ingredients and techniques of local chefs also often differ from those in restaurants serving the same cuisine outside of the local context, such as in tourists' home countries or ethnic meals that these tourists may prepare in their own kitchens. These factors all add to the allure of the experience of local food at a destination.

Globalization can facilitate an understanding of different cultures. Through increasing exposure to diverse national and regional cuisines due to globalization and an increase in the number of food-related TV programmes, magazines and online platforms, people around the world are increasingly motivated to try different kinds of food, such as ethnic and traditional food at a destination, and accept differences in food cultures (Chang, Kivela, \& Mak, 2011). People often search for information on restaurants and cuisines, including famous dishes, at their intended travel destinations. Other tourists' reviews are sought, using food-related functions of online platforms such as TripAdvisor.

Chinese tourists represent an increasingly substantial segment of the global travel market. According to Li (2017), there were 133 million outbound Chinese tourists in 2016, and Chinese international tourism is predicted to continue to increase in the coming years. Chinese tourists are becoming increasingly willing to spend on services during their travels (Ryall, 2017), including on food and beverage-related services.

Although Hong Kong is politically a Special Administrative Region (SAR) of the People's Republic of China, it is considered an outbound destination for mainland Chinese tourists because it maintains a visa and immigration policy that is separate and distinct from that of the Chinese nation, and Chinese nationals require a special entry permit to visit. Hong Kong also has its own separate currency, political and legal systems (McKercher \& Zhang, 2017).

Importantly for this research, while Hong Kong exists within the broad Chinese cultural sphere, it also has its own unique cuisine. There are many Chinese regional cuisines, and indeed Hong Kong is an epicentre of Cantonese cuisine, one of the socalled 'Eight Great Cuisines' of China (the others are Anhui, Fujian, Hunan, Jiangsu, Shandong and Zhejiang). Additionally, demonstrating one facet of the influence of globalisation on local cuisine, because of its colonial, cosmopolitan history, Hong Kong's food also shows influences of other global cuisines, making its culinary offerings unique within China and the world. Consequently, local food is a strong distinguishing factor for Hong Kong as a tourism destination, even for Chinese tourists.

Academic research into food tourism has grown significantly in recent years. Previous research on food tourism has focused on the use of local cuisines in marketing and promoting the regional identity of a destination (Everett \& Aitchison, 2008; Horng \& Tsai, 2012; Okumus, Okumus, \& McKercher, 2007; Tse \& Crotts, 2005) and is seen as a motivation to travel to a tourist destination (Kim, Eves, \& Scarles, 2009; Mitchell \& Hall, 2003). Several researchers also suggest ways to categorize food consumption preferences (Hjalager, 2004; Ottenbacher et al., 2016; Sengel et al., 2015; UNWTO, 2017).

However, there have been few studies related to Chinese tourists' preferences regarding food experiences while traveling (Chang, Kivela, \& Mak, 2010; Wu, Raab, 
Chang, \& Krishen, 2016). Wu et al. (2016) investigate factors that determine Chinese tourists' food consumption while traveling in the United States, finding that food's sensory appeal has a positive effect on motivating consumption while concerns about food safety and differences in table manners exert a negative influence.

The tendency of Chinese tourists to travel in organized packaged tours in which there is a low degree of individual choice in deciding what or where to eat, and a high tendency for tour organizers to stay with 'safe' food options appealing to the least-commondenominator of mass-market food preferences, contribute to individuals' lack of chances to explore local cuisines while traveling. Past studies have investigated Chinese tourists' food consumption in the context of such mass tours. For instance, Chang et al. (2010) survey Chinese tourists on package tours to Australia. However, there is an increasing number of independent Chinese travellers who do not travel on package tours (Yip \& Pratt, 2018). A recent estimate suggests that $60 \%$ of Chinese outbound tourists (70 million) are non-package tourists (World Travel Online, 2017). Nonetheless, the importance of such individual travellers has been largely overlooked in previous research.

In this study, we apply Hjalager (2004) four types of food lifestyles (recreational, existential, diversionary and experimental) and adapt Kim et al.'s (2009) eight motivational factors of local food consumption to understand Chinese tourists' travel food experiences. Gaining an understanding of motivations and perceptions based on these categorizations can help destination marketing organizations and the wider tourism industry to understand Chinese tourists' food experiences while traveling. According to Kim et al. (2009), physical surroundings, health concerns, excitement, prestige, escaping from routine, togetherness, acquiring knowledge, sensory appeal and authenticity are primary factors in tourists' motivations for local food consumption.

Using a quantitative method, this study aims to achieve the following objectives: 1) to understand the types of food experiences Chinese outbound tourists have while traveling, 2) to determine the importance of the factors that influence Chinese tourists' intention to consume local food, and 3) to provide recommendations for DMOs for the marketing of food to Chinese travellers. Food is considered an effective element of destination marketing and Chinese tourists are a market with high growth potential. Hong Kong was selected as an ideal location for this study because it is one of the destinations with the highest concentration of Chinese tourists outside of the Chinese mainland, providing a large and rich pool of potential respondents. This study will help develop an understanding of the preferences and motivational factors in the travel dining experience of this important market.

\section{Literature review}

As noted above, there is an increasing body of knowledge concerning food tourism, sometimes referred to as culinary tourism or gastronomy tourism. This body of knowledge has branched into several areas. Scholars have examined the link between destination marketing and the cultural aspects of food (Chang et al., 2010; Cohen \& Avieli, 2004; Horng \& Tsai, 2012; Okumus et al., 2007; Telfer \& Wall, 2000; Tse \& Crotts, 2005). Some have also investigated underlying motivational factors of food consumption on travel destinations (Fields, 2003; Jiménez Beltrán, López-Guzmán, \& Santa-Cruz, 2016; Kim et al., 2009). Another stream of 
research has examined the experiential dimension of food in the tourism context (Björk \& Kauppinen-Räisänen, 2016; Hjalager, 2004; Sengel et al., 2015).

\section{Food as tourism segment and a destination marketing strategy}

Food tourism is defined as 'visitation to primary and secondary food producers, food festivals, restaurants and specific locations for which food tasting and/or experiencing the attributes of specialist food production region are the primary motivating factor for travel' (Hall \& Mitchell, 2001, p. 308). This implies that a visit to a restaurant while abroad, in and of itself, may not necessarily be considered a food tourism activity, if the primary motivating factor for the visit is for sustenance rather than for a food experience (Hall \& Sharples, 2004). Food tourism is thus defined in terms of motivation rather than in terms of the nature of the activity alone.

For the purposes of this research, local food is defined as cuisine that is specific to a particularly geographically circumscribed locality, prepared and consumed within this locality. The geographical realm of a local cuisine can be at the scale of a nation (in the case of smaller countries), a sub-national region or province, a city, neighbourhood or even a particular restaurant or other gastronomic establishment.

Food tourism is a type of special interest tourism. As defined by McKercher, Okumus, and Okumus (2008, p. 139), special interest tourism is tourism motivated by a pronounced interest in a topic, perspective or type of activity that becomes 'the hub around which the total travel experience is planned and developed'. Food tourism can be considered one of the more recently-emerging and fastest-growing forms of special interest tourism, and more and more destinations are seeking to attract tourists through their local cuisine to diversify their target source markets. Food tourism can also assist destinations in marketing and enhancing their regional identity in the tourism market, which can be an effective component in reviving tourism at destinations (Kivela \& Crotts, 2006).

The local food of a destination is a strategic element in tourism marketing, as it represents an experience that is characteristic of the place and which distinguishes it from other places and from tourists' home cultures (Björk \& Kauppinen-Räisänen, 2016; Choe, Kim, \& Cho, 2017; Henderson, 2009; Horng \& Tsai, 2012; Okumus \& Cetin, 2018; Okumus et al., 2007; Tsai \& Wang, 2017). It is deeply tied to the culture and destination image of a place (Björk \& Kauppinen-Räisänen, 2016; Jolliffe, 2016). Local food has been demonstrated to be an important factor in destination selection and intention to re-visit a place for a majority of tourists (Ab Karim \& Chi, 2010; Silkes, Cai, \& Lehto, 2013). Marketing around local food can take place through various channels, such as events and social media platforms (Tan \& Hashim, 2013; Viljoen, Kruger, \& Saayman, 2018). Local food is a central and explicit element of the Hong Kong Tourism Board in marketing the city as a destination (Horng \& Tsai, 2012); http://www.discoverhongkong.com/us/dine-drink/index.jsp). Destination marketing organisations of the Basque (https://tourism.euskadi.eus/en/\#) and Catalan (Londoño, 2011) regions of Spain are other examples of subnational DMOs promoting local food tourism.

\section{Cultural influences on food preferences}

Previous research has demonstrated how food preferences and food-related behaviour vary according to the home culture of the tourists in question. According to Cohen and 
Avieli (2004), sharing food during a trip is seen as less favourable by Westerners than by Asian tourists. In Thailand, even when Westerners are 'sharing' food, they are typically served a local meal in miniature 'individualized' sets so that eating from a shared dish is avoided (Cohen \& Avieli, 2004, p. 763). Telfer and Wall (2000) suggest that Asian tourists tend to consume Asian dishes while visiting Indonesia whereas Europeans tourists may demand more international foods rather than local cuisines. Similarly, Chang et al. (2010) found that, even while abroad, Chinese food remains the dominant food preference of Chinese tourists. The two most essential factors influencing Chinese tourists' food preference are appetizing cuisine and familiar flavour. Palatability and group harmony are also important for Chinese tourists (Chang et al., 2010).

\section{Motivational factors for food consumption}

Fields (2003) proposes four categories of motivations for food consumption: physical motivators, cultural motivators, interpersonal motivators, and status and prestige motivators. Physical motivators have to do with the embodied experience during the trip. The taste, presentation and aroma of food are examples of elements of the physical experience. Seeking a healthy diet or a diet for weight-loss or general wellness are also possible components of this motivator. Cultural motivators have to do with interest in learning about and participating in foreign cultures and lifestyles through culinary experiences. Interpersonal motivators involve the social dimensions of food experiences. Tourists often spend time eating with friends and family members during a trip, which can contribute to the forging or strengthening of relationships. Status and prestige motivators draw on the social capital associated with dining in up-scale restaurants or acquiring other food experiences that set the tourist apart from other members of their society, after which tourists share their experience with others on social media or in face-to-face interactions.

Kim et al. (2009) expanded on Fields' (2003) four factors to include nine motivations for local food consumption by tourists: physical surroundings, health concerns, excitement, prestige, escaping from routine, togetherness, acquiring knowledge, sensory appeal and authenticity. These motivations can be grouped into two main categories: the symbolic dimension and the obligatory dimension (Mak, Lumbers, \& Eves, 2012). The symbolic dimension of food relates to its cultural and educational aspects. The preparation, presentation and consumption of local foods are important ways for tourists to gain knowledge about a culture. The symbolic dimension concerns food as an experience. The obligatory dimension of food pertains to the increase in perceived risk presented by foreign and unfamiliar food and cuisines during travel, in which there are increased opportunities to try unusual foods. Kim et al's (2009) excitement and prestige belong to the symbolic dimension while health concerns and physical surroundings pertain to the obligatory dimension. These motivational factors are employed in this study to distinguish the various types of motivations of Chinese tourists in their food consumption habits abroad.

Studies suggest that the first of Kim et al's categories, physical surroundings, has a significant effect on customers' intention to choose a restaurant (Meiselman, Johnson, Reeve, \& Crouch, 2000; Yüksel \& Yüksel, 2003). Kim et al. (2009) identified aspects of the physical surroundings that appeal to tourists, finding that they value eating environments that are perceived as 'clean', 'big', 'looks nice' and 'historical' (Kim et al., 2009, p. 428). 
Some tourists are motivated by health concerns, the second category, when dining while traveling. Tourists tend to think that local food made with local ingredients are fresher and healthier (Kim et al., 2009). The use of local ingredients can enhance the appearance and flavour of food and can also decrease environmental impact by reducing 'food miles'. People are becoming more conscious of nutrition, weight control and healthy lifestyles (Glanz, Basil, Maibach, Goldberg, \& Snyder, 1998; Lockie, Lyons, Lawrence, \& Grice, 2004). In a study by Sparks, Bowen, and Klag (2003), over half of the respondents reported that when dining out on vacation, consuming healthy food is one of the main considerations.

Trying unfamiliar food can be an invigorating experience, and expectations of an experience offering excitement can enhance the experience (Rust \& Oliver, 2000). Tourists may seek out such experiences by reading the accounts of previous travellers on social media.

Tourists may also be motivated by prestige, involving a quest for social acceptance and admiration (Kim et al., 2009). According to Fields (2003), the need to gain acceptance from one's friends and peers is one of the reasons that some tourists dine out during a trip. They often share pictures and information with their friends of the food they tried during their travels to boost their self-esteem and gain admiration within their peer group.

Some tourists are looking for novelty to experience unfamiliar kinds of eating experiences (Hjalager, 2004). Davidson (2002) and Fields (2003) indicate that people sometimes like to travel to escape from routine of their daily patterns and try new things, including new foods.

Togetherness with friends and family while eating is one of the main reasons for traveling for many people (Ignatov \& Smith, 2006). Personal relationships and social bonds can be strengthened by eating together, and sharing food experiences with members of one's close familial or social group can boost the pleasure of the culinary experience (Warde \& Martens, 2000).

Acquiring knowledge about a local culture can be achieved through culinary experiences at a destination. Food is perceived as a facet of the cultural heritage of a destination (Mitchell \& Hall, 2003). According to Mak et al. (2012, p. 178), culture capital can be divided into three types, which are 'the embodied state (the knowledge and skills an individual possesses), the objectified state (expressed in a form of cultural goods), and the institutionalized state (represented by actual documents and other proof of cultural status)'. Food is considered an embodied state of cultural capital since consuming local food is a way for tourists to acquire knowledge about local food and culture. For example, tourists may learn about a new culture by understanding the reasons and traditions behind using a certain cooking method and ingredients in local cuisine.

The sensory appeal of food - its smell, taste and visual appearance - is central to the culinary experience. The appearance of food and the aesthetic appeal of the cooking performance can add value to the food experience. As explained by Fields (2003), taste remains the most significant factor in sensory appeal, and thus a vital factor in attracting tourists who are interested in local food.

Pursuing authenticity is one of the reasons why tourists try local foods during their trip. Food can be different at a foreign destination than in the tourist's home culture, 
and tourists who value this dimension want to feel that they are experiencing the food in its authentic form (Ritzer \& Liska, 1997). Originality and uniqueness of food are considered factors of authenticity of the food experience (Kim et al., 2009).

Motivations are closely related to psychology, and the relationship between psychological factors and food choice has been explored in a number of studies (Chang et al., 2011; Fischler, 1988; Mak et al., 2012; Pliner \& Salvy, 2006). The psychological concepts of food neophobia and neophilia are of particular relevance when discussing people's relationships to foreign foods. Neophobic people tend to refuse new and unfamiliar foods while neophilic individuals seek out new and value unfamiliar food experiences (Chang et al., 2010). Tourists can be segmented based on the extent to which they are neophobic or neophilic, that is whether the prefer novelty or familiarity in their cuisine. These different motivational segments also correspond to different categories in the experiential dimension of food, as will be discussed in the following section.

\section{Food experiences}

Food experiences can be separated into several types. Hjalager (2004) classifies food 'lifestyles' into four categories: recreational, existential, diversionary and experimental, which we further extrapolate to reframe this distinction in terms of different experiential preferences. In this sense, the experiences associated with existential and experimental food lifestyles imply a preference for novelty, which can be seen as appealing to neophilic psychological predilections, while the experiential preferences that characterise recreational and diversionary lifestyles are associated with familiarity, which correspond more with neophobic tendencies. We adopt the categories proposed by Hjalager to denote the types of experiences implicit in each of the four lifestyles.

Following this logic, those seeking existential experiences appreciate simple, local and traditional food experiences. They prefer visiting restaurants where local people eat instead of those frequented by other tourists. Outside of the restaurant, existential tourists prefer to extend their food experience in tourism through activities such as visiting working farms and vineyards, harvesting fruits and vegetables and joining cooking classes.

Keeping up with trends and fashion are factors for tourists seeking experimental food experiences. Smart design, chic service, new ingredients, innovative menus and unfamiliar or unconventional ways of eating and preparing food, are valued by tourists with a preference for experimental experiences.

Recreational experiences are preferred by people who value familiarity. Tourists in this category are less willing to dine out and less attracted by the atmosphere, food quality and service quality of a foreign restaurant. Local cuisines in foreign countries are less valued by this group of travellers, who often choose to cook for themselves when possible in order to have familiar food. They are not particularly interested in food-related entertainment, especially if it requires their active participation (Kivela \& Crotts, 2006).

The last segment is tourists seeking diversionary experiences. A primary purpose of a trip for these tourists is to escape from the routine of daily life. Familiar food in sufficient quantities is essential for them. However, food is not their main concern. The focus of their dining experiences is to enjoy life and socialize with friends and new acquaintances. Therefore, eating places with noise and laughter are preferred. Casual service and dress code are also important. 
Apart from the motivation factors of food consumption (Kim et al., 2009) and the four categories of food experiences (Hjalager, 2004), a distinction should also be made between food as a consumptive experience and food as a peak touristic experience (Mak et al., 2012; Quan \& Wang, 2004). Consumptive food experiences are those that sustain and reaffirm daily routines, which can provide comfort and help in overcoming anxieties brought about by new environments (Quan \& Wang, 2004). Peak touristic experiences, on the other hand, contrast to daily routines, providing new insights and a sense of adventure (Urry, 2002).

These four categories of food experiences; existential, experimental, diversionary and recreational are used in this paper to investigate food experiences of individual Chinese tourists. The methods used to collect data to investigate this issue will be explained in the following section.

\section{Methodology}

To understand the types of food experiences Chinese outbound tourists have while traveling and to determine the importance of the factors that influence these tourists' intention to consume local food, we adapt the research framework developed by Hjalager (2004) and the motivational factors in travel dining experiences suggested by Kim et al. (2009). The framework is shown in the figure below:

\section{Target population and sampling}

The target population for this research is Chinese (People's Republic of China) outbound tourists. Questionnaires were distributed by two means. One distribution method was through online social media which targeted younger respondents. The survey questions were prepared in a Google document that potential respondents could complete using their electronic devices, computers and smart phones to access. An internet hyperlink to the Google document was shared through the Facebook, Instagram and WeChat accounts of one the authors. As such, convenience sampling was undertaken. Potential respondents in one of the author's social media network were asked to share the link within their social media networks, hence facilitating snowball sampling. The benefits of collecting data via an online survey is that data collection is efficient and economical but there are limitations to this distribution method. Distributing an online survey through a researcher's social media means that often, potential respondents are of the same demographics (age, education) as the researcher, which can skew the sample (Pratt \& Chan, 2016). Other scholars have used social media, such as Facebook, to facilitate data collection and show that it is a successful and effective recruitment method (Ramo \& Prochaska, 2012). It is more affordable than email surveys or other traditional recruitment mechanisms, such as hiring a survey sampling company.

Another data collection method was undertaken targeting older potential respondents through in-person interview surveys. One of the authors visited locations in Hong Kong that were known to be heavily frequented by mainland Chinese tourists, including the Avenue of Stars in Tsim Sha Tsui and the Star Ferry Terminal on Hong Kong Island. The author approached every fifth person who walked past a designated point at each of those commonly-frequented tourist spots. Potential respondents were informed of the purpose of the survey, told that the interview was for research purposes only and informed that 
they could withdraw from the survey at any time. Potential respondents were told the approximate length of the survey (eight minutes) and assured that all information they provided would remain confidential and their responses would be aggregated with other responses and only used for statistical purposes. The data collection was done in March 2018 and lasted approximately four weeks.

At the end of the data collection period, 308 usable responses were received, giving a maximum sampling error of $\pm 5.6 \%$. The dataset was entered into SPSS for further analysis.

\section{Survey instrument}

The survey instrument consisted of five sections. In the first section, two screening questions determined whether the potential respondent was a People's Republic of China national and whether they were a visitor to Hong Kong. A second section asked about travel history and the main purpose of the trip. A third section captured the tourist's preferences in food experiences and travel dining experiences using a 5-point Likert agreement scale. As noted above, the items pertaining to preference for food experiences were adapted from Hjalager (2004) and Sengel et al. (2015) and the travel dining experience items (16 in total) were adapted from Kim et al. (2009). One dependent variable, the likelihood to consume local food while traveling, was measured on a 5-point Likert scale where 1 was 'extremely unlikely' and 5 was 'extremely likely'. The fifth and final section contained a standard set of demographic questions capturing age, gender, marital status, highest level of education attained, occupation and monthly household income.

The English questionnaire was pre-tested among five English-speaking undergraduate university students for completeness and comprehensibility, as a result of which minor changes in wording were made. The questionnaire was then translated into Chinese by one of the authors, who is bi-lingual in English and Chinese. The Chinese version of the questionnaire was then tested again among five other Chinese-speaking undergraduate students to ensure ease of understanding.

Table 1 shows the profile of the sample for this research. Almost two-thirds of the sample were female (63.6\%) and a high proportion $(50.0 \%)$ were students. This naturally corresponds to a younger cohort $(18-24$ years $=58.1 \%)$, single $(77.9 \%)$ with a bachelor's degree level of education (79.5\%) and relatively low income, with $50 \%$ earning less than RMB 10,000 ( US\$ 1,500) per month. Nearly two-thirds $(66.2 \%)$ of this cohort travel internationally one or two times a year, with another $21.4 \%$ traveling abroad between three and five times a year. The main purposes of their trip to Hong Kong were for food (80.5\%) and shopping (77.6\%), corresponding to Hong Kong's established destination image (Leung, Law, \& Lee, 2011; Yeung, Kim, \& Schuckert, 2016). Visiting friends and relatives was another significant reason (36.4\%).

The relatively young cross-section of Chinese society represented by the sample implies that the results can be seen as indicative of the habits and perceptions of a generation of Chinese who have unprecedented freedom to travel and contact with global culture (through digital forums) and a globalising Chinese culture (Corigliano, 2011). The high proportion of college-educated respondents means that the sample would be seen as a subset of the population with a higher degree of cultural perspective and intellectual 
Table 1. Sample profile.

\begin{tabular}{lrlr}
\hline Gender & & Monthly household income level \\
Male & $36.4 \%$ & Lower than RMB 10,000 & $50.0 \%$ \\
Female & $63.6 \%$ & RMB 10,000-18,999 & $18.9 \%$ \\
Age & & RMB 19,000-27,999 & $15.4 \%$ \\
$18-24$ years & $58.1 \%$ & RMB 28,000-36,999 & $11.4 \%$ \\
$25-34$ years & $20.1 \%$ & RMB 37,000 or above & $4.4 \%$ \\
$35-44$ years & $9.7 \%$ & Approximately, how often do you travel internationally per year? \\
$45-54$ years & $6.5 \%$ & This is my first trip out of mainland China & $7.5 \%$ \\
55 years or above & $5.5 \%$ & $1-2$ times per year & $66.2 \%$ \\
Marital Status & & $3-5$ times per year & $21.4 \%$ \\
Single & $77.9 \%$ & More than 5 times per year & $4.9 \%$ \\
Married & $17.9 \%$ & What is the main purpose of this trip? & \\
Widowed or Divorced & $4.2 \%$ & Food & $80.5 \%$ \\
Education level & & Shopping & $77.6 \%$ \\
Secondary school & $6.8 \%$ & Visiting friends and relatives & $36.4 \%$ \\
Vocational school & $1.0 \%$ & Sightseeing/Relaxation & $12.6 \%$ \\
Undergraduate/Bachelor Degree & $79.5 \%$ & Education and training & $8.4 \%$ \\
Postgraduate Degree or above & $12.7 \%$ & Business & $3.6 \%$ \\
Occupation & & Religion & $2.3 \%$ \\
Student & $50.0 \%$ & Health and medical care & $0.6 \%$ \\
Employed & $41.2 \%$ & & \\
Self-employed & $0.6 \%$ & & \\
Housewife & $5.2 \%$ & & \\
Retired & $1.3 \%$ & & \\
Unemployed & $1.6 \%$ & & \\
\hline
\end{tabular}

* Multiple responses allowed

† RMB 10,000 US\$1,500

refinement (which would also be expected to represent a segment of society that has both the means and the curiosity to travel) (Gardiner \& Kwek, 2017).

\section{Data analysis}

To understand the nature of the types of food experiences Chinese outbound tourists have while traveling, we use descriptive statistics to determine which characteristics Chinese outbound tourists feel best describe their experiences and motivations as pertains to food in the context of travel. To determine the importance of the factors that influence Chinese tourists' intention to consume local food, we undertake regression analysis of the conceptual framework shown in Figure 1. We test to see if the dependent variable 'Q5. You are likely to consume local food during travel' is normally distributed. The Shapiro-Wilk test rejects the null hypothesis (statistic $=0.836, \mathrm{df}=308, \mathrm{p}<0.00$ ) that this variable is normally distributed. The distribution of the dependent variable is not normally distributed. There are few responses for 'Extremely likely $=5$ ' and few responses for 'Extremely unlikely $=1$ ' and ' 2 '. Therefore, despite the question initially being asked on a 5 -point Likert scale, respondents answered either ' 3 ' or ' 4 ', almost de facto in a binary manner. Therefore, we transform this dependent variable into a binary variable in the following way (Table 2) so that 0 is 'unlikely' and 1 is 'likely':

To determine which motivation factors best explain the likelihood of consuming local food while traveling, a logistic regression was run since the dependent variable is dichotomous. Logistic regression uses the maximum likelihood method of estimation. The independent variables are composite mean scores for each of the eight motivation 


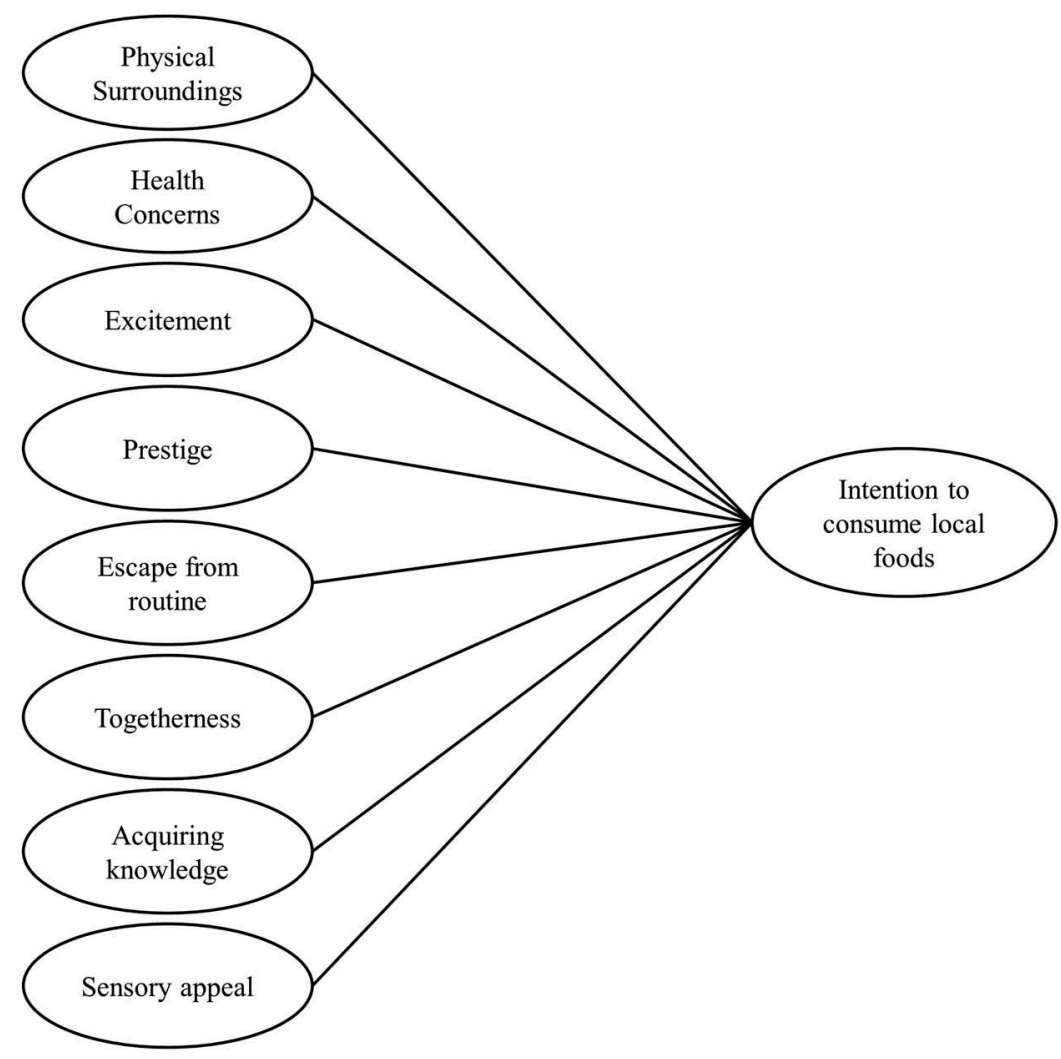

Figure 1. Motivation factors framework for intention to consume local foods.

Table 2. Dependent variable.

\begin{tabular}{lcccc}
\hline Q5. You are likely to consume local food during travel & $\mathrm{n}$ & $\%$ & Transformed Variable \\
\hline Extremely unlikely & 1 & 0.3 & 56.8 & Unlikely \\
2 & 21 & 6.8 & & Likely \\
3 & 153 & 49.7 & 43.2 & \\
4 & 114 & 37.0 & 6.2 & 100 \\
Extremely likely & 19 & 100 &
\end{tabular}

factors shown in Table 3. Each factor, containing two items, exhibits a high degree of internal consistency (Cronbach's alphas all > 0.7).

\section{Results}

Table 3 shows the descriptive statistics for preference for food experiences and food motivations among Chinese outbound tourists to Hong Kong. In terms of mean scores, the interviewed Chinese tourists were more likely to seek existential and diversionary experiences and less likely to seek experimental and recreational experiences. The highest scoring item was 'Q3.1 Visit restaurants that local people like instead of restaurants popular among tourists' (3.77 out of 5). 'Q3.8 Visit lively and friendly 
Table 3. Descriptive statistics of preference for food experiences and food motivations.

\begin{tabular}{|c|c|c|c|}
\hline Preference for Food Experiences & a & Mean & S.D \\
\hline Existential Experiences & 0.793 & 3.63 & 0.616 \\
\hline Q3.1 Visit restaurants where local people like instead of visiting tourist or popular restaurant & & 3.77 & 0.691 \\
\hline $\begin{array}{l}\text { Q3.2 Visit working farms and vineyards, harvest fruits and vegetables and joining cooking } \\
\text { class }\end{array}$ & & 3.50 & 0.663 \\
\hline Experimental Experiences & 0.872 & 2.94 & 0.757 \\
\hline Q3.3 Visit trendy and fashionable restaurants & & 2.89 & 0.812 \\
\hline Q3.4 Visit restaurants with smart design, chic service, new ingredients and innovative menus & & 2.99 & 0.797 \\
\hline Recreational Experiences & 0.886 & 2.96 & 0.764 \\
\hline Q3.5 Buy local ingredients and cook for themselves instead of going out & & 2.92 & 0.819 \\
\hline Q3.6 Have familiarized food in fast food or chain restaurants & & 2.99 & 0.793 \\
\hline Diversionary Experiences & 0.841 & 3.54 & 0.678 \\
\hline Q3.7 Visit restaurants with casual service and dress code & & 3.49 & 0.692 \\
\hline Q3.8 Visit lively and friendly dining places & & 3.59 & 0.767 \\
\hline Motivational Factors to Consume Local Foods & a & Mean & S.D \\
\hline Physical Surroundings & 0.701 & 4.06 & 0.571 \\
\hline Q4.1 Cleanliness of the restaurants is important for your travel dining experience & & 4.05 & 0.671 \\
\hline Q4.2 Design of the restaurants is important for your travel dining experience & & 4.06 & 0.648 \\
\hline Health & 0.827 & 3.54 & 0.633 \\
\hline Q4.3 Nutrition is important for your travel dining experience & & 3.54 & 0.676 \\
\hline $\begin{array}{l}\text { Q4.4 Use of food materials with fresh appearance and flavour is important for your travel } \\
\text { dining experience }\end{array}$ & & 3.55 & 0.695 \\
\hline 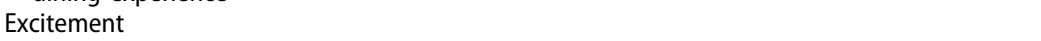 & 0.778 & 3.73 & 0.639 \\
\hline $\begin{array}{l}\text { Q4.5 Before travel, you search for food, which the image make you feel excited, on social } \\
\text { media or other medium }\end{array}$ & & 3.85 & 0.706 \\
\hline $\begin{array}{l}\text { Q4.6 When you eat out, it is exciting for you to try the most unusual items, even if you are } \\
\text { not sure you would like them }\end{array}$ & & 3.62 & 0.705 \\
\hline Prestige & 0.859 & 3.99 & 0.672 \\
\hline $\begin{array}{l}\text { Q4.7 It is important for you to share photos and information of your dining experience with } \\
\text { others through social platform }\end{array}$ & & 3.99 & 0.704 \\
\hline $\begin{array}{l}\text { Q4.8 You will go to restaurants recommended by your surrounding social groups and the } \\
\text { public }\end{array}$ & & 3.99 & 0.731 \\
\hline Escape from Routine & 0.831 & 3.88 & 0.573 \\
\hline $\begin{array}{l}\text { Q4.9 You feel comfortable when you try food in trip which is different from that you eat in } \\
\text { your normal life }\end{array}$ & & 3.88 & 0.605 \\
\hline $\begin{array}{l}\text { Q4.10 Your choices and behaviour for dining experience during travel is different from your } \\
\text { daily life }\end{array}$ & & 3.89 & 0.633 \\
\hline Togetherness & 0.850 & 3.07 & 0.66 \\
\hline Q4.11 Socializing with your friends is important for yc & & 3.08 & 0.731 \\
\hline Q4.12 Socializing with your family is important for your travel dining experience & & 3.06 & 0.682 \\
\hline Acquiring Knowledge & 0.875 & 3.83 & 0.752 \\
\hline Q4.13 You want to know more about other countries through your travel dining experience & & 3.85 & 0.811 \\
\hline $\begin{array}{l}\text { Q4.14 You would like to know about new ingredients and cooking methods used on your } \\
\text { travel dining experience }\end{array}$ & & 3.81 & 0.783 \\
\hline Sensory Appeal & 0.780 & 3.19 & 0.602 \\
\hline Q4.15 The food display is important for your travel dining experience & & 3.28 & 0.646 \\
\hline Q4.16 Live cooking performance is important for your travel dining experience & & 3.10 & 0.683 \\
\hline
\end{tabular}

$a=$ Cronbach's Alpha; S.D = Standard Deviation

dining places' also ranked highly (3.59). The lowest ranked item was 'Q3.3 Visit trendy and fashionable restaurants' (2.89). 'Q3.5 Buy local ingredients and cook for themselves instead of going out' also ranked low (2.92).

For the motivational factors for consuming local food, physical surroundings and prestige are the highest-rated. Both of the items pertaining to physical surroundings, 'Q4.1 Cleanliness of the restaurants is important for your travel dining experience' and 'Q4.2 Design of the restaurants is important for your travel dining experience' were given an average score of over 4.0 (4.05 and 4.06, respectively). The items under prestige were rated 
slightly lower, both with a mean score of 3.99. The lowest-scoring motivation factors are togetherness (3.07) and sensory appeal (3.19).

Table 4 shows the results of the logistic regression. The pseudo R-squares, the Cox \& Snell $\mathrm{R}^{2}$ and Nagelkerke $\mathrm{R}^{2}$, demonstrate that these eight motivational factors show a moderate fit for explaining the likelihood to consume local food while traveling. The Cox and Snell $R^{2}(31.0 \%)$ is usually lower than Nagelkerke's $R^{2}(41.6 \%)$. The regression reveals that five factors; excitement, prestige, escape from routine, acquiring knowledge and sensory appeal, are all significant $(\mathrm{p}<0.05)$ determinants of the likelihood to consume local food while traveling. The $\operatorname{Exp}(\beta)$ column in Table 4 shows the odds ratio of the independent variables. They are the exponentiation of the coefficients. An increase in one unit of the sensory appeal factor is associated with being 3.8 times more likely to consume local food while traveling. An increase in one unit on the acquiring knowledge agreement scale is associated with being 2.75 times more likely to consume local food while traveling. Other significant factors in order of impact on the dependent variable are prestige, escape from routine and excitement.

\section{Discussion and conclusions}

The above-discussed findings give clues as to how to position current Chinese outbound tourists relative to developmental trends in the tourism industry, in the context of globalisation in which Chinese are coming into contact with foreign cultures through information and travel, to an unprecedented degree.

The high value put on 'Visit[ing] restaurants that local people like instead of visiting restaurants popular among tourists' contrasts with the common group tour practice of dining together in large tourist groups in restaurants that cater to such tours. This could be seen as indicative of the increasing tendency of Chinese tourists to travel independently rather than with organized tours (Yip \& Pratt, 2018). On the other hand, the low value assigned to 'Buy local ingredients and cook for themselves instead of going out' indicates that this niche would be less likely to participate in cooking classes and other participatory food experiences that are becoming increasingly popular with other market segments (Bell, 2015; Therkelsen, 2015; Walter, 2017).

These are identified examples of broader trends among respondents to this survey of preference for existential and diversionary experiences and relative disregard for experiences that are recreational or experimental, referring to experiences pertaining to Hjalager's (2004) four food lifestyles. The interviewed tourists in general valued

Table 4. Logistic regression for likelihood to consume local food while traveling.

\begin{tabular}{lrrrrrr}
\hline Variables in the Equation & $\beta$ & S.E. & Wald & df & p-value & $\operatorname{Exp}(\beta)$ \\
\hline Constant & -17.24 & 2.51 & 47.00 & 1 & 0.000 & 0.00 \\
Physical Surroundings & 0.11 & 0.29 & 0.14 & 1 & 0.704 & 1.12 \\
Health & 0.02 & 0.25 & 0.01 & 1 & 0.940 & 1.02 \\
Excitement & $\mathbf{0 . 5 0}$ & $\mathbf{0 . 2 5}$ & $\mathbf{3 . 9 0}$ & $\mathbf{1}$ & $\mathbf{0 . 0 4 8}$ & $\mathbf{1 . 6 4}$ \\
Prestige & $\mathbf{0 . 7 4}$ & $\mathbf{0 . 2 5}$ & $\mathbf{8 . 7 0}$ & $\mathbf{1}$ & $\mathbf{0 . 0 0 3}$ & $\mathbf{2 . 1 0}$ \\
Escape from Routine & $\mathbf{0 . 6 2}$ & $\mathbf{0 . 3 0}$ & $\mathbf{4 . 3 3}$ & $\mathbf{1}$ & $\mathbf{0 . 0 3 7}$ & $\mathbf{1 . 8 7}$ \\
Togetherness & 0.32 & 0.23 & 1.87 & 1 & 0.172 & 1.37 \\
Acquiring Knowledge & $\mathbf{1 . 0 1}$ & $\mathbf{0 . 2 3}$ & $\mathbf{1 9 . 4 7}$ & $\mathbf{1}$ & $\mathbf{0 . 0 0 0}$ & $\mathbf{2 . 7 5}$ \\
Sensory Appeal & $\mathbf{1 . 3 3}$ & $\mathbf{0 . 2 9}$ & $\mathbf{2 1 . 1 9}$ & $\mathbf{1}$ & $\mathbf{0 . 0 0 0}$ & $\mathbf{3 . 7 9}$ \\
\hline
\end{tabular}

Cox \& Snell R Square = 31.0\%; Nagelkerke R Square = 41.6\%; S.E. = Standard error; $\mathrm{df}=$ Degrees of freedom. 
experiences that make them feel immersed in the local culture and which take them mentally out of the routine of their day-to-day lives, while putting less value on food experiences that conform to their accustomed eating habits, or which are associated with unconventional or innovative food concepts. This shows that no clear generalization can be made as to neophilic or neophobic tendencies (Chang et al., 2010) in this group, as one of the two preferred categories (existential) is associated with noveltyseeking behaviour while the other (diversionary) is linked to a desire for familiarity.

Both of Kim et al.'s (2009) factors corresponding most directly to (Mak et al., 2012) symbolic dimension (excitement and prestige) were found to be significant determinants of likelihood to consume local food while traveling. In addition to the aforementioned two factors, three other of Kim et al.'s (2009) nine motivators for eating local food were identified as significant: escape from routine, acquiring knowledge and sensory appeal. These tourists are motivated by the promise of local food experiences to get them out of their day-to-day eating habits, to learn about the local culture and for the multi-sensory (smell, taste and look) appeal of the culinary experience.

As such, Hong Kong restaurants would be advised to heighten the sensory appeal components of the dining experience as this factor has the potential to increase the likelihood to consume local food while traveling the most. The visual presentation is important for these travellers and opportunities to see the food being prepared is another way to enhance the food experience. No consistent correlation was found between the rank of a given factor as a motivator and its influence on desire to eat local foods while at a destination. Of the five significant determinant factors, one (prestige) ranked particularly high as a motivating factor, one (sensory appeal) rated particularly low, and the other three were neither remarkably high nor low.

The five identified factors indicate that the Chinese tourists with the greatest desire to try local food abroad are those who value food experiences that are new and unusual and that give them social capital among their peer group, who see these experiences as offering diversion from day-to-day routine, seek to learn about foreign cultures through food and appreciate the gustatory, olfactory and aesthetic pleasures of cuisine. This implies that promotional campaigns and communication that present destination food experiences as exciting, prestigious, out-of-the-ordinary, educational and sensory are more likely to appeal to those Chinese tourists who are most likely to seek out local food at the destination.

This profile does not sit completely within any of Hjalager's (2004) four food lifestyles, but can be described as exhibiting elements of existential and diversionary tendencies. They are drawn by existential food experiences in that they like to eat in restaurants where locals eat and have above average interest in some other food experiences like visiting farms (see Table 3). Their alignment with the diversionary profile is more mixed. They value local food experiences as a way to escape from their everyday routine, but show no pronounced concern for the socializing aspects of local food experiences. Hjalager's categories must be understood not as mutually exclusive and it is likely that any given tourist or sector of tourists will display characteristics that are a hybrid of these tendencies.

On the other hand, the likelihood of eating local food while traveling was found to be influenced to a much lesser degree by whether a particular tourist prioritizes the healthiness of food, appreciates the qualities of the environment within which the food is consumed or values the social dimension of food experiences. This indicates that communications accentuating the nutritional value of the food would not be particularly effective for 
Chinese tourists, against the international trend identified by other researchers (Glanz et al., 1998; Lockie et al., 2004). The atmosphere of eating establishments or conviviality in the dining experience are also less likely to strike a chord with Chinese travellers.

These findings give clear indications for destination management organisations and even individual eating establishments seeking to attract the outbound Chinese tourist market. They demonstrate that certain broad stereotypes (as identified for instance by Chang et al., 2010) about Chinese tourists preferring their own national cuisine when traveling abroad are overly simplistic, or that habits and preferences of this tourism market are changing over time as they become more accustomed to travel abroad. Likewise, the lack of importance of togetherness as a factor also runs counter to earlier research (Ignatov \& Smith, 2006) and also contradicts broad stereotypes of Asian travellers. This tourism niche is in fact distinguished by a nuanced set of preferences and motivations.

The questions asked pertained to respondents' general preferences regarding the consumption of food while traveling and not only specifically about Hong Kong cuisine. Accordingly, although no claims are made at unequivocal generalizability of the findings, the results do constitute a baseline that can be tested and validated (or otherwise) in subsequent research on Chinese tourists to other destinations.

As with most research, there are limitations that future research could overcome. This study was a cross-sectional quantitative study. The sample is skewed relatively young so that, while Chinese Generation $\mathrm{Y}$ are an important market and a worth subject of study (Agyeiwaah, Suntikul, \& Li, 2018), the sample is not wholly representative of the Chinese outbound tourist market to Hong Kong. The data was collected indestination. The benefit of this is that Chinese outbound tourists have the eating-out experience fresh in their minds. Alternatively, it would be interesting to conduct a study pre-trip and post-trip to compare and contrast Chinese outbound tourists' food motivations and food experiences. This would enable the DMO, restaurants and other eating-places, to assess the expectations and fulfilment or otherwise of food tourists. An in-depth qualitative study could be implemented to follow up some of the findings and issues raised in this research. Methodologies that enable more probing could strengthen insights. To build upon the knowledge presented here, future research could extend the profile of general preferences of Chinese tourists with studies of their relationship and attitudes towards the local cuisines of particular destinations. The insights drawn from applying Hjalager's food lifestyles as a reference for defining different types of local food preferences among Chinese tourists also invite future studies seeking to use this framework to profile the proclivities of other national groups in their motivations to eat local food at destinations.

\section{Disclosure statement}

No potential conflict of interest was reported by the authors.

\section{Notes on contributors}

Wantanee Suntikul is an Assistant Professor in School of Hotel and Tourism Management at The Hong Kong Polytechnic University, 17 Science Museum Road, TST East, Hong Kong (E-mail: w.suntikul@polyu.edu.hk). 
Stephen Pratt is Professor and Head of School of Tourism \& Hospitality Management, The University of the South Pacific, Laucala Campus, Suva, Fiji (E-mail: Stephen.pratt@usp.ac.fj).

Yu Wing Johnny Chong was a student in School of Hotel and Tourism Management at The Hong Kong Polytechnic University, 17 Science Museum Road, TST East, Hong Kong (E-mail: yu-wing.chong@connect.polyu.hk).

\section{ORCID}

Wantanee Suntikul (D) http://orcid.org/0000-0002-3834-850X

Stephen Pratt (D) http://orcid.org/0000-0002-6550-132X

\section{References}

Ab Karim, S., \& Chi, C. G.-Q. (2010). Culinary tourism as a destination attraction: An empirical examination of destinations' food image. Journal of Hospitality Marketing \& Management, 19 (6), 531-555.

Agyeiwaah, E., Suntikul, W., \& Li, C. Y. S. (2018). 'Cool Japan': Anime, soft power and Hong Kong generation Y travel to Japan. Journal of China Tourism Research, 15(2), 127-148.

Bell, C. (2015). Tourists infiltrating authentic domestic space at Balinese home cooking schools. Tourist Studies, 15(1), 86-100.

Björk, P., \& Kauppinen-Räisänen, H. (2016). Exploring the multi-dimensionality of travellers' culinary-gastronomic experiences. Current Issues in Tourism, 19(12), 1260-1280.

Chang, R. C., Kivela, J., \& Mak, A. H. (2010). Food preferences of Chinese tourists. Annals of Tourism Research, 37(4), 989-1011.

Chang, R. C., Kivela, J., \& Mak, A. H. (2011). Attributes that influence the evaluation of travel dining experience: When East meets West. Tourism Management, 32(2), 307-316.

Choe, J. Y., Kim, J. H., \& Cho, M. S. (2017). A comparison of food contents used by official tourism organizations' mobile applications. Journal of Gastronomy and Tourism, 2(3), 203-216.

Cohen, E., \& Avieli, N. (2004). Food in tourism: Attraction and impediment. Annals of Tourism Research, 31(4), 755-778.

Corigliano, M. A. (2011). The outbound Chinese tourism to Italy: The new graduates' generation. Journal of China Tourism Research, 7(4), 396-410.

Davidson, A. (2002). The wilder shores of gastronomy: Twenty years of the best food writing from the journal petits propos culinaires. Berkeley, CA: Ten Speed Press.

Everett, S., \& Aitchison, C. (2008). The role of food tourism in sustaining regional identity: A case study of Cornwall, South West England. Journal of Sustainable Tourism, 16(2), $150-167$.

Fields, K. (2003). Demand for the gastronomy tourism product: Motivational factors. In A.M. Hjalager \& G. Richards (Eds.), Tourism and gastronomy (pp. 36-50). London, UK: Routledge.

Fischler, C. (1988). Food, self and identity. Information (International Social Science Council), 27 (2), 275-292.

Gardiner, S., \& Kwek, A. (2017). Chinese participation in adventure tourism: A study of generation Y international students' perceptions. Journal of Travel Research, 56(4), 496-506.

Glanz, K., Basil, M., Maibach, E., Goldberg, J., \& Snyder, D. (1998). Why Americans eat what they do: Taste, nutrition, cost, convenience, and weight control concerns as influences on food consumption. Journal of the American Dietetic Association, 98(10), 1118-1126.

Hall, C. M., \& Mitchell, R. (2001). Wine and food tourism. In N. Douglas \& R. Derrett (Eds.), Special interest tourism: Context and cases (pp. 307-329). Brisbane, Australia: Wiley.

Hall, C. M., \& Sharples, L. (2004). The consumption of experiences or the experience of consumption? An introduction to the tourism of taste. In C. M. Hall, L. Sharples, 
R. Mitchell, N. Macionis, \& B. Cambourne (Eds.), Food tourism around the world (pp. 1-24). London: Routledge.

Henderson, J. C. (2009). Food tourism reviewed. British Food Journal, 111(4), 317-326.

Hjalager, A. M. (2004). What do tourists eat and why? Towards a sociology of gastronomy and tourism. Tourism (Zagreb), 52(2), 195-201.

Horng, J.-S., \& Tsai, C.-T. (2012). Exploring marketing strategies for culinary tourism in Hong Kong and Singapore. Asia Pacific Journal of Tourism Research, 17(3), 277-300.

Ignatov, E., \& Smith, S. (2006). Segmenting Canadian culinary tourists. Current Issues in Tourism, 9(3), 235-255.

Jiménez Beltrán, J., López-Guzmán, T., \& Santa-Cruz, F. G. (2016). Gastronomy and tourism: Profile and motivation of international tourism in the city of Córdoba, Spain. Journal of Culinary Science \& Technology, 14(4), 347-362.

Jolliffe, L. (2016). Marketing culinary tourism experiences. In M. Sotiriadis \& D. Gursoy (Eds.), The handbook of managing and marketing tourism experiences (pp. 363-378). Bingley, West Yorkshire: Emerald.

Kim, Y. G., Eves, A., \& Scarles, C. (2009). Building a model of local food consumption on trips and holidays: A grounded theory approach. International Journal of Hospitality Management, 28(3), 423-431.

Kivela, J., \& Crotts, J. C. (2006). Tourism and gastronomy: Gastronomy's influence on how tourists experience a destination. Journal of Hospitality \& Tourism Research, 30(3), 354-377.

Leung, D., Law, R., \& Lee, H. A. (2011). The perceived destination image of Hong Kong on Ctrip. com. International Journal of Tourism Research, 13(2), 124-140.

Li, J. (2017). Record 133 million Chinese tourists to travel out of mainland this year, with Hong Kong their top destination. South China Morning Post. Retrieved from http://www. scmp.com/news/china/money-wealth/article/2017633/record-number-chinese-tourists-traveloutside-mainland-year

Lockie, S., Lyons, K., Lawrence, G., \& Grice, J. (2004). Choosing organics: A path analysis of factors underlying the selection of organic food among Australian consumers. Appetite, 43(2), 135-146.

Londoño, M. D. P. L. (2011). Gastronomy tourism: An opportunity for local development in Catalonia? A stakeholder analysis. Retrieved from http://core.ac.uk/download/pdf/6580310.pdf

Mak, A. H., Lumbers, M., \& Eves, A. (2012). Globalisation and food consumption in tourism. Annals of Tourism Research, 39(1), 171-196.

McKercher, B., Okumus, F., \& Okumus, B. (2008). Food tourism as a viable market segment: It's all how you cook the numbers!. Journal of Travel \& Tourism Marketing, 25(2), 137-148.

McKercher, B., \& Zhang, R. (2017). Hong Kong as a supranational destination for Chinese tourists. Journal of China Tourism Research, 13(2), 178-192.

Meiselman, H. L., Johnson, J. L., Reeve, W., \& Crouch, J. E. (2000). Demonstrations of the influence of the eating environment on food acceptance. Appetite, 35(3), 231-237.

Mitchell, R., \& Hall, C. M. (2003). Consuming tourists: Food tourism consumer behaviour. In C. M. Hall, L. Sharples, R. Mitchell, N. Macionis, \& B. Cambourne (Eds.), Food tourism around the world (pp. 60-80). Oxford: Routledge.

Okumus, B., \& Cetin, G. (2018). Marketing Istanbul as a culinary destination. Journal of Destination Marketing \& Management, 9, 340-346.

Okumus, B., Okumus, F., \& McKercher, B. (2007). Incorporating local and international cuisines in the marketing of tourism destinations: The cases of Hong Kong and Turkey. Tourism Management, 28(1), 253-261.

Ottenbacher, M. C., Harrington, R. J., Fauser, S., \& Loewenhagen, N. (2016). Should culinary tourism and hospitality service attributes be defined as primary tourism drivers? An expectancy-fulfillment grid approach. Journal of Foodservice Business Research, 19(5), 425-440.

Pliner, P., \& Salvy, S. (2006). Food neophobia in humans. In R. Shepherd \& M. Raats (Eds.), Frontiers in nutritional science (pp. 75-92). Wallingford, UK: CABI.

Pratt, S., \& Chan, W. S. (2016). Destination image and intention to visit the Tokyo 2020 Olympics among Hong Kong Generation Y. Journal of China Tourism Research, 12(3-4), 355-373. 
Quan, S., \& Wang, N. (2004). Towards a structural model of the tourist experience: An illustration from food experiences in tourism. Tourism Management, 25(3), 297-305.

Ramo, D. E., \& Prochaska, J. J. (2012). Broad reach and targeted recruitment using Facebook for an online survey of young adult substance use. Journal of Medical Internet Research, 14(1), e28.

Ritzer, G., \& Liska, A. (1997). McDisneyization" and "Post-Tourism": Complementary perspectives on contemporary tourism. In C. Rojek \& J. Urry (Eds.), Touring cultures: Transformations of travel and theory (pp. 96-109). London: Routledge.

Rust, R. T., \& Oliver, R. L. (2000). Should we delight the customer? Journal of the Academy of Marketing Science, 28(1), 86-94.

Ryall, J. (2017). End of the boom? 'Explosive shopping' by Chinese tourists in Japan may be on the wane. Retrieved from http://www.scmp.com/news/asia/east-asia/article/2062513/end-boomexplosive-shopping-chinese-tourists-japan-may-be-wane

Sengel, T., Karagoz, A., Cetin, G., Dincer, F. I., Ertugral, S. M., \& Balık, M. (2015). Tourists' approach to local food. Procedia-Social and Behavioral Sciences, 195, 429-437.

Silkes, C. A., Cai, L. A., \& Lehto, X. Y. (2013). Marketing to the culinary tourist. Journal of Travel \& Tourism Marketing, 30(4), 335-349.

Sparks, B., Bowen, J., \& Klag, S. (2003). Restaurants and the tourist market. International Journal of Contemporary Hospitality Management, 15(1), 6-13.

Stone, M. J., Soulard, J., Migacz, S., \& Wolf, E. (2018). Elements of memorable food, drink, and culinary tourism experiences. Journal of Travel Research, 57(8), 1121-1132.

Tan, S. T., \& Hashim, N. H. (2013). An investigation into official tourism websites for promoting food tourism in ASEAN countries. Asia-Pacific Journal of Innovation in Hospitality and Tourism, 2(2), 171-182.

Telfer, D. J., \& Wall, G. (2000). Strengthening backward economic linkages: Local food purchasing by three Indonesian hotels. Tourism Geographies, 2(4), 421-447.

Therkelsen, A. (2015). Catering for yourself: Food experiences of self-catering tourists. Tourist Studies, 15(3), 316-333.

Tsai, C.-T., \& Wang, Y.-C. (2017). Experiential value in branding food tourism. Journal of Destination Marketing \& Management, 6(1), 56-65.

Tse, P., \& Crotts, J. C. (2005). Antecedents of novelty seeking: International visitors' propensity to experiment across Hong Kong's culinary traditions. Tourism Management, 26(6), 965-968.

UNWTO. (2017). Second global report on gastronomy tourism. Retrieved from http://cf.cdn. unwto.org/sites/all/files/pdf/gastronomy_report_web.pdf

Urry, J. (2002). The tourist gaze: Theory, culture \& society (2nd ed.). London: SAGE Publications.

Viljoen, A., Kruger, M., \& Saayman, M. (2018). The art of tastings: Enhancing the arts festival experience. International Journal of Event and Festival Management, 9(3), 246-265.

Walter, P. (2017). Culinary tourism as living history: Staging, tourist performance and perceptions of authenticity in a Thai cooking school. Journal of Heritage Tourism, 12(4), 365-379.

Warde, A., \& Martens, L. (2000). Eating out: Social differentiation, consumption and pleasure. Cambridge, UK: Cambridge University Press.

World Travel Online. (2017). Chinese outbound tourism statistics in 2016: 122 million Chinese tourists make outbound trips, spend \$109.8 billion. Retrieved from http://news.travel168.net/ 20170203/43145.html

Wu, K., Raab, C., Chang, W., \& Krishen, A. (2016). Understanding Chinese tourists' food consumption in the United States. Journal of Business Research, 69(10), 4706-4713.

Yeung, M. W., Kim, S., \& Schuckert, M. (2016). Japanese tourists to Hong Kong: Their preferences, behavior, and image perception. Journal of Travel \& Tourism Marketing, 33(5), 730-741.

Yip, L., \& Pratt, S. (2018). The evolution of Chinese mainland visitors to Hong Kong from international visitors to domestic visitors. Journal of China Tourism Research, 14(3), 354-369.

Yüksel, A., \& Yüksel, F. (2003). Measurement of tourist satisfaction with restaurant services: A segment-based approach. Journal of Vacation Marketing, 9(1), 52-68. 